\title{
Diretrizes para prevenção de manifestações patológicas em Habitações de Interesse Social
}

\author{
Guidelines for the prevention of pathological \\ manifestations in Social Housing
}

\section{Carolina Lemos Carraro João Fernando Dias}

\section{Resumo}

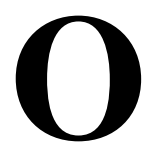

$\mathrm{s}$ programas habitacionais do governo visam combater o déficit brasileiro que gira em torno de sete milhões de habitações. A preocupação quantitativa, nem sempre articulada com políticas urbanas e sociais, incentiva a produção de conjuntos habitacionais com soluções urbanísticas, arquitetônicas e construtivas repetitivas em larga escala. Diante desta realidade preocupante, o presente estudo visa contribuir para melhorar a qualidade construtiva de empreendimentos habitacionais de interesse social e diminuir o impacto ambiental causado pela sua degradação prematura. A abordagem metodológica adotada foi estudo de caso exploratório. Foi realizada uma investigação das manifestações patológicas no conjunto habitacional Jardim das Palmeiras, situado na cidade de Uberlândia-MG. Neste empreendimento, o sistema construtivo e materiais empregados eram tradicionais, representando as tecnologias típicas da indústria da construção brasileira. As principais contribuições do trabalho referem-se às possíveis origens das manifestações patológicas e à retroalimentação para processo de projeto, gestão da construção e utilização das habitações de interesse social.

Palavras-chave: Habitação de Interesse Social. Manifestações patológicas. Qualidade. Durabilidade de construções. PAR - Programa de Arrendamento Residencial.

Carolina Lemos Carraro Carraro Arquitetura Araguari - MG - Brasil

João Fernando Dias Universidade Federal de Uberlândia Uberlândia - MG - Brasil

Recebido em 09/12/13 Aceito em 12/04/14

\section{Abstract}

The Brazilian government's housing programs aim to solve the housing shortage, which is currently around seven million homes. The quantitative concern, not always articulated with urban and social policies, encourages the production of social housing using large scale and repetitive urban, architectural and construction solutions. In the face of this troubling reality, this study aims to contribute to improve the building quality of new housing projects, as well as to reduce the environmental impact caused by their premature degradation. The research approach adopted was exploratory case study. An investigation on the pathological manifestations in the Jardim das Palmeiras social housing project, in Uberlândia, State of Minas Gerais, was undertaken. In this project the building materials and sub-systems were fairly traditional, representing typical technologies used in the Brazilian construction industry. The main contributions of this research work are related to the origins of pathological manifestations, and feedback to the processes of design, construction management and use of social housing projects.

Keywords: Social housing. Pathological manifestations. Quality. Durability of buildings. PAR - Residential Leasing Program. 


\section{Introdução}

Este trabalho está baseado em pesquisa de dissertação de mestrado, na linha de construção civil, do Programa de Pós-Graduação em Engenharia Civil da Universidade Federal de Uberlândia e representa uma sequência na linha da pesquisa de Pereira (2008).

A pesquisa foi realizada em um momento de mudanças na política habitacional brasileira, quando o Governo Federal buscava diminuir o grande déficit habitacional, à época em torno de sete milhões de habitações (MINISTÉRIO..., 2009).

Em 2007 foi lançado o Programa de Aceleração do Crescimento (PAC), pelo qual foi previsto um investimento em habitação de R $\$ 27,5$ bilhões para aquele ano e de $\mathrm{R} \$ 78,8$ bilhões entre os anos de 2008 e 2010 (MÁXIMO, 2007).

No mesmo ano, o Programa de Arrendamento Residencial (PAR), criado em 1999, sofreu alterações por meio da Lei n. 11.474 (BRASIL, 2007). Segundo Reis (2008), essa lei alterou o "espírito" da lei original ao adicionar a possibilidade da alienação dos imóveis adquiridos no âmbito do programa sem prévio arrendamento, além de possibilitar que, a partir do quinto ano de pagamento regular do arrendamento, o arrendatário pudesse antecipar a opção de compra.

Em março de 2009 foi lançado um novo plano habitacional, Minha Casa, Minha Vida, com os objetivos de construir um milhão de moradias e de gerar emprego e renda por meio do aumento do investimento na construção civil. Sua implantação prevê subsídios e desonerações que somam R \$ 34 bilhões (BLANCO, 2009).

Em junho de 2009 entrou em vigor a Lei n. 11.888 (BRASIL, 2008), que garante a assistência técnica gratuita, prestada por engenheiros e arquitetos, a quem mora no campo ou na cidade e quer construir, reformar e ampliar, ou mesmo fazer a regularização fundiária de casa com até $60 \mathrm{~m}^{2}$, localizada em áreas de interesse social (BRASIL, 2008).

Diante desse cenário de crescimento potencial e com um histórico de problemas, é necessário, no mínimo, refletir sobre a qualidade da habitação de interesse social, pois a qualidade deficiente resulta em desperdício de recursos públicos, ineficiência no combate ao déficit habitacional e impactos socioeconômicos e ambientais negativos.

Roméro e Vianna (2002) chamaram a atenção sobre a realidade dos conjuntos habitacionais, o impacto em termos de habitação social que irradia nas vizinhanças e na cidade, a satisfação de seus usuários e as eventuais demandas latentes, assim como sobre a qualidade da própria unidade habitacional e do conjunto como um todo, para prevenir o surgimento de epidemias muito comuns em cortiços e em favelas.

Os mesmos autores abordam a importância de o conjunto habitacional oferecer para sua população condições ambientais de qualidade, possibilitando cultivar e mesmo melhorar a cultura urbana, ou seja, seus hábitos de viver em comunidade, exercendo seus direitos e respeitando o próximo.

Entende-se assim que o ato de morar demanda um esforço considerável em termos de educação social e ambiental, pedindo mudanças de comportamento em prol da "construção" de uma comunidade em que cada membro usufrua as vantagens oferecidas em seu conjunto habitacional, ao mesmo tempo em que contribui para a manutenção dessas qualidades ambientais. Precisam criar sua própria cultura.

No início dos anos 90, ocorreu a elaboração dos principais programas da qualidade da construção civil brasileira a partir da evolução do conceito da qualidade, da necessidade de adequação das normas NBR ISO 9000 às particularidades da indústria da construção civil e da constatação da necessidade de melhoria na qualidade dos edifícios. Assim surgiram as primeiras iniciativas de programas de implantação de Sistemas de Gestão da Qualidade (SGQ) adaptados ao setor da construção civil. Nesse contexto insere-se o Programa Brasileiro da Qualidade e Produtividade no Habitat (PBQP-H), que se propõe a organizar o setor da construção civil em torno da melhoria da qualidade e da modernização produtiva, gerando um ambiente de isonomia competitiva.

Um dos projetos propulsores do PBQP-H é o Sistema de Avaliação da Conformidade de Empresas de Serviços e Obras (SiAC), que é o resultado da reestruturação do antigo Sistema de Qualificação de Empresas de Serviços e Obras (SiQ). O SiAC tem como objetivo avaliar a conformidade do sistema de gestão da qualidade das empresas de serviços e obras, considerando as características específicas da atuação dessas empresas no setor da construção civil, e tem correspondência com a série de normas ISO 9000. Busca contribuir para a evolução dos patamares de qualidade do setor, envolvendo especialidades técnicas de execução de obras, serviços especializados de execução de obras, gerenciamento de obras e de empreendimentos, e elaboração de projetos (PROGRAMA..., 2008).

Entretanto, observam-se dificuldades das empresas construtoras para a efetiva implementação dos 
SGQs em suas obras. Pereira (2008) concluiu que o fato de a empresa apresentar um SGQ implantado não é sinônimo de se atingir a qualidade necessária no produto final - no caso a habitação de interesse social (HIS). Essa autora identificou diversas falhas na fase de execução da obra, entre elas deficiências no PQO e em sua aplicação efetiva no canteiro de obras.

Diante da deficiência de qualidade presente no setor da construção civil, Cleto et al. (2011) discutiram a necessidade de criação do Códigos de Práticas no Brasil, abordando as técnicas identificadas como as melhores para se realizarem determinadas atividades, podendo-se definir também a melhor forma de atuar dos profissionais que as executam. Identificaram que essa atividade poderia ser simplificada com o uso dos referenciais tecnológicos ou códigos de prática que definissem critérios de avaliação de processos construtivos. Reiteraram ainda a relevância do tema em razão do aumento significativo da construção de habitações, devido ao Programa "Minha Casa, Minha Vida", do Governo Federal, incitando à mobilização dos agentes da oferta e da demanda do setor para a continuidade do sistema.

Preocupações como as apresentadas por Cleto et al. (2011) demonstram a importância das pesquisas. Questões diversas estão a ser respondidas, como o que mais pode ser feito pela qualidade dos conjuntos habitacionais, quais são os problemas recorrentes encontrados nas construções, por que há recorrência dos mesmos problemas construtivos e tantas manifestações patológicas, como fissuras, infiltrações, desgaste de revestimento, que continuam se repetindo, mesmo nesse segmento construtivo tão simples como o das habitações de interesse social.

Mais recentemente, preocupados com essa temática, Berr e Formoso (2012) reconheceram a importância de haver disponíveis informações consistentes sobre o desempenho de processos e técnicas construtivas durante a execução. Relataram os autores as dificuldades de avaliar a qualidade das edificações, diante de diferentes interpretações e nomenclaturas das partes e itens de verificação nas diferentes regiões do país. Desenvolveram, então, um método para avaliação da qualidade de processos construtivos em empreendimentos habitacionais de interesse social.

Alertaram esses autores que estabelecer uma conduta de aferição da qualidade com o foco nos processos em execução poderia eliminar problemas de conformidade ocultos sob outros processos subsequentes e possibilitar ações de caráter mais proativo.
A construção industrializada, pré-fabricada, ou a pré-fabricação de sistemas e subsistemas construtivos, seria uma alternativa à construção tradicional, mas para isso seria necessário introduzir características inerentes à industrialização da construção, como produção em larga escala, com padronização, repetibilidade, alta produtividade e gestão precisa.

Silva e Barros (2013) propõem um modelo de planejamento de processos de construção para a produção industrializada de edifícios habitacionais que consiste em uma ferramenta de gestão direcionada ao planejamento direto das atividades de produção e, por isso, constitui uma contribuição para o desenvolvimento da construção industrializada de edifícios. As autoras afirmam que sua implantação estimula a organização a pensar detalhadamente sobre seus processos, o que contribui para evidenciar falhas e oportunidades de melhoria, levando a uma produção eficiente, que é o objetivo principal da industrialização da construção.

O planejamento de processos é destacado por Roy, Low e Waller (2005), uma vez que processos bem definidos e otimizados apresentam maior potencial de economia, contribuindo, assim, para uma melhor eficiência da construção.

No entanto, ainda não é uma realidade no país o emprego de processos industrializados em larga escala, aplicados aos empreendimentos habitacionais de interesse social. Algumas técnicas construtivas surgiram como alternativa à construção convencional, para a execução de paredes, e têm sido empregadas em alguns empreendimentos habitacionais de interesse social. A investigação de processos industrializados não é escopo deste trabalho, mas pode-se dizer que o simples fato de se empregarem técnicas diferentes de execução de subsistemas da construção não é garantia de eliminação do surgimento dos defeitos construtivos, o que reforça a tese de Berr e Formoso (2012) para a avaliação da qualidade dos processos construtivos em empreendimentos habitacionais de interesse social.

Por outro lado, no Reino Unido, a introdução de sistemas construtivos industrializados é considerada por Pan, Gibb e Dainty (2007) como um grande desafio para oferecer habitações em quantidade, com a produtividade e qualidade necessárias. Os próprios construtores oferecem resistência à incorporação de novas técnicas construtivas, expondo as divergências entre a indústria de pré-fabricados e a da construção civil. São barreiras relacionadas com questões culturais, maior investimento, dificuldade de alcançar economia de escala, interface complexa entre os 
sistemas construtivos, impossibilidade de manter o projeto inicial, aversão ao risco, fragmentação da indústria e também as preocupações manifestas dos agentes financiadores e seguradoras com relação aos processos construtivos não tradicionais.

Os dados obtidos no presente trabalho corroboram as preocupações de Berr e Formoso (2012), trazendo fatos relacionados a manifestações patológicas em um conjunto habitacional de interesse social, executado mediante o sistema construtivo convencional ou tradicional, em continuidade à pesquisa de Pereira (2008). Os problemas aqui relatados podem ser encarados como uma consequência de deficiências nas etapas anteriores analisadas pela autora mencionada, referidas ao empreendimento. Dessa forma, a partir da análise da menor parte - a unidade habitacional e seus elementos construtivos -, este trabalho vislumbra contribuir com o todo - o planejamento habitacional.

\section{Programa de Arrendamento Residencial (PAR)}

O PAR é um programa do Ministério das Cidades operacionalizado pela CAIXA e financiado pelo FAR. Surgiu em 1999, visando atender à necessidade de moradia da população de baixa renda, prioritariamente concentrada nos grandes centros urbanos, sob a forma de arrendamento residencial, com opção de compra ao final do prazo contratado. Segundo Brito (2009), o arrendamento se assemelha em alguns aspectos à locação social difundida nos países europeus. Porém, conforme citado anteriormente, o PAR sofreu alterações por meio da Lei n. 11.474 (BRASIL, 2007). Foi adicionada a possibilidade de alienação dos imóveis adquiridos no âmbito do programa sem prévio arrendamento, e a antecipação da opção de compra a partir do quinto ano de pagamento regular de arrendamento (BRASIL, 2007).

O empreendimento é realizado pela iniciativa privada e tem como objetivo reduzir o déficit habitacional das capitais e respectivas regiões metropolitanas, e municípios com mais de 100.000 habitantes.

A CAIXA avalia as propostas apresentadas sob os aspectos técnicos de engenharia, jurídico, análise cadastral, avaliação de risco de crédito, viabilidade do empreendimento, taxa de urbanização do município e demais análises estabelecidas para o Programa (CAIXA..., 2010). Para essas avaliações, a CAIXA possui um Caderno de Orientação de Empreendimentos (COE), o qual estabelece os critérios adotados.
Os imóveis adquiridos pelo PAR podem ser empreendimentos na planta, em construção, concluídos ou para reforma/recuperação. Conforme a Cartilha do PAR (CAIXA..., 2008), o programa destina-se a famílias cuja renda varia de acordo com a modalidade do imóvel, sua localidade e a data de aquisição/execução do empreendimento.

O arrendatário deve utilizar o imóvel com a destinação específica de residência dele e de sua família, assumindo todas as despesas e tributos incidentes sobre o imóvel, e tem a obrigação de mantê-lo em perfeitas condições de habitabilidade e conservação durante o prazo de arrendamento. Ele deve ocupar o imóvel no prazo máximo de 90 dias após a assinatura do contrato.

\section{Acompanhamento de obras - CAIXA}

De acordo com o COE (CAIXA..., 2004), o engenheiro ou arquiteto da CAIXA realiza visitas ao empreendimento para verificar a evolução da obra sob a óptica de garantia do financiamento. Fica a cargo do proponente, no caso, da construtora, a verificação diária da qualidade de execução do produto e o cumprimento dos projetos e dos memoriais descritivos. A CAIXA não se responsabiliza pela fiscalização da execução dos serviços e aplicação dos diversos materiais, por não manter um profissional diariamente na obra.

A verificação pela CAIXA do desempenho da construtora ou da qualidade da obra é feita através de visitas à obra, quando é preenchido o Relatório de Acompanhamento de Empreendimento (ERA), e está relacionada a fatores que possam vir a comprometer a garantia financeira no empréstimo concedido. Porém, através dessa verificação, ela acompanha o nível de certificação alcançada no PBPQ-H pela construtora, agregando efetividade ao Programa.

\section{Manifestações patológicas das construções}

As manifestações patológicas das construções podem ser entendidas, analogamente à ciência médica, como o ramo da engenharia que estuda os sintomas, formas de manifestação, origens e causas das doenças ou defeitos que ocorrem nas edificações.

Segundo Carmona Filho (2009), é uma ciência relativamente nova, que estuda os diversos problemas a que as construções estão sujeitas, sejam eles decorrentes de falhas de projeto, de execução, mau uso ou o envelhecimento natural das edificações. 
Para Helene (1992), “[...] pode ser entendida como parte da engenharia que estuda os sintomas, os mecanismos, as causas e as origens dos defeitos das construções civis, ou seja, é o estudo das partes que compõem o diagnóstico do problema [...]”. E afirma que um diagnóstico será adequado e completo quando esclarecer todos os aspectos do problema: sintomas, mecanismo, origem, causas e consequências.

Neste trabalho, os sintomas ou manifestações patológicas são classificados em quatro tipos: umidade, descolamento de revestimento, fissuras e irregularidade do acabamento.

\section{Origem}

Segundo Thomaz (2001), a agência Qualiform, com base em levantamentos executados por companhias seguradoras francesas na década de 80, apontava como origem das manifestações patológicas as seguintes estatísticas: projetos $42 \%$; processos de construção - $24 \%$; materiais $17 \%$; uso indevido das obras - $10 \%$; e outras origens (acidentes, erosão, etc.) - 7\%. Tal pesquisa, que confirma resultados de tantas outras, aponta o projeto como maior responsável pelas manifestações patológicas das construções. O autor afirma que as "falhas de projeto" compreendem operações de construção que foram mal executadas por falta de detalhamento, omissões ou equívocos dos projetos relativos aos materiais e às técnicas construtivas.

Segundo Fiess et al. (2004), falhas de execução compreendem aqueles serviços que apresentam manifestações patológicas em razão da falta de controle dos serviços, omissão de alguma especificação que conste em projeto e falta de cumprimento da normalização técnica.

E para os mesmos autores, falhas provenientes da qualidade dos materiais compreendem aqueles elementos que, independentemente da qualidade de seu projeto e/ou execução, encontram-se deteriorados.

Já as falhas decorrentes do uso dizem respeito àqueles elementos que foram prejudicados pela falta das atividades necessárias à garantia de seu desempenho satisfatório ao longo do tempo (SOUZA; RIPPER, 1998).

\section{Causas}

A causa das manifestações patológicas, de acordo com Helene (1992), está relacionada a vários fenômenos que influenciam no surgimento das anomalias. Merecem destaque cargas excessivas, variações de umidades, variações térmicas, agentes biológicos, incompatibilidade de materiais, agentes atmosféricos, entre outros.

\section{Consequências}

Um bom diagnóstico deve ter condições de prever as consequências futuras que o problema poderá trazer no comportamento geral do edifício. Helene (1992) separa esses prognósticos em dois tipos: os que afetam as condições de segurança da estrutura (mais urgentes); e os que comprometem somente as condições de higiene e estética, denominadas condições de serviços, associadas aos estadoslimite de utilização.

Para Helene (1992), a manutenção preventiva é a maneira mais barata e correta de se manter em boas condições de uso uma edificação. A falta de uma manutenção preventiva durante o uso do edifício pode até quintuplicar o custo para a realização de uma ação.

As medidas corretivas são os reparos dos problemas levantados durante os trabalhos de diagnóstico, prognóstico e desenvolvimento das formas de intervenção. A essas atividades pode-se associar, geralmente, um custo de aproximadamente 125 vezes superior ao custo das medidas que poderiam ter sido tomadas durante as fases iniciais da construção (HELENE, 1992).

\section{Objetivo}

Este trabalho tem como objetivo geral contribuir com o processo de projeto, gestão da construção e utilização das habitações de interesse social, ao oferecer diretrizes para a prevenção das manifestações patológicas em novos empreendimentos, relacionadas aos documentos que regem o sistema.

Os objetivos específicos desta pesquisa são:

(a) identificar e descrever as manifestações patológicas encontradas nas unidades de um conjunto habitacional na cidade de Uberlândia; e

(b) relacionar as manifestações patológicas com as possíveis origens de sua ocorrência, a partir do exame documental.

\section{Metodologia}

Para a pesquisa base da dissertação de mestrado foi feita uma pesquisa teórica e revisão bibliográfica consultando livros, teses e dissertações, artigos científicos, normas técnicas, além de publicações em jornais e revistas e internet. Foram abordados os seguintes temas: habitação de interesse social, avaliação pós-ocupação, elementos construtivos convencionais, manifestações patológicas, gestão e 
ciclo de vida de empreendimentos, manutenção predial, e sustentabilidade. Esta revisão se deu a fim de colocar a pesquisadora a par do que já havia sido estudado, publicado, e quais os resultados obtidos sobre o tema de pesquisa proposto.

Foram levantadas também todas as informações sobre o PAR, por meio de pesquisas eletrônicas nos sites do governo e da CAIXA (órgão responsável por sua implantação), além de entrevistas com funcionários desta instituição. Essas informações foram necessárias para que se compreendessem quais diretrizes, atividades e atributos do programa da CAIXA poderiam influenciar nas manifestações patológicas encontradas, visto que o conjunto habitacional estudado foi implantado por esse programa.

Iniciando-se o estudo de caso, realizou-se uma visita prévia no local de estudo, onde, com entrevistas semiestruturadas, seguindo o modelo de Roméro e Ornstein (2003), foram colhidas informações de alguns arrendatários.

Durante as visitas também foi realizado um registro fotográfico para se documentar com dados concretos o que ocorreu logo após a ocupação das HIS.

Para a abordagem das unidades habitacionais, adotaram-se aqui os procedimentos apresentados por Ornstein e Roméro (1992) e por Ribeiro e Echeveste (1998) na constituição de amostragem representativa do todo.

O tamanho da amostra final, neste trabalho, compreendeu 13 unidades habitacionais, cuja seleção foi feita por meio de amostragem aleatória simples, procurando situações diversas de implantação do lote, haja vista a importância da orientação solar.

Foram realizadas vistorias técnicas qualitativas por meio de observação direta durante as visitas de inspeção, com correspondentes registros fotográficos e anotações em planilhas estruturadas, para facilitar o trabalho no campo. E assim como nas visitas prévias, também foram realizadas entrevistas semiestruturadas com os mutuários do conjunto habitacional.

As planilhas utilizadas para anotações de campo e organização do levantamento das manifestações patológicas observadas foram formuladas de acordo com a experiência vivida durante as visitas prévias e também a partir da análise de fichasmodelo e planilhas de Azevedo et al. (2008), Fiess et al. (2004) e Thomaz (2001). Elas contêm a planta do imóvel, com a respectiva orientação do norte indicada, onde foi sinalizada a localização dos registros fotográficos.

As manifestações patológicas foram observadas visualmente, identificadas e tabuladas, para permitir a análise posterior das possíveis origens, a partir da análise documental, com o intuito de se visualizarem medidas preventivas.

Sendo assim, os resultados obtidos foram sintetizados em diagramas e, a partir daí, analisados, visando à conexão do conteúdo documental com as falhas encontradas. $\mathrm{O}$ intuito foi verificar se nos documentos do empreendimento existem falhas que propiciem a ocorrência das manifestações encontradas, ou seja, encontraram-se manifestações patológicas nas unidades, embora o PAR tenha em seu bojo diversos elementos documentais controlados, entre eles projetos, memoriais, manuais.

\section{Conjunto habitacional}

O conjunto habitacional estudado está localizado no município de Uberlândia, em loteamento aprovado em 2003, a $11 \mathrm{~km}$ do centro da cidade.

O empreendimento foi implantado através do PAR. Tanto os projetos como o orçamento e cronograma físico-financeiro foram submetidos à aprovação da CAIXA. O prazo para realização da obra foi em média de 12 meses para todas as empresas.

Ele foi dividido entre quatro empresas, uma responsável pela construção de 200 unidades, enquanto as outras ficaram com 100 unidades cada, totalizando o máximo permitido pelo PAR, 500 unidades habitacionais, com área mínima do lote de $250 \mathrm{~m}^{2}$. Este trabalho contempla o estudo de 13 das 100 unidades da empresa A (Figura 1).

\section{Identificação dos fenômenos patológicos}

Com a planilha estruturada em mãos, as visitas de inspeção foram realizadas. Nessas planilhas foram assinaladas as localizações das anomalias para futura quantificação das incidências (Figura 2). Essa marcação se deu por meio de números, para que posteriormente pudesse ser relacionada com a fotografia registrada (Figura 3). Tais anomalias foram verificadas através da observação direta, e também por meio de entrevista com o mutuário. 
Figura 1 - Foto aérea do conjunto habitacional

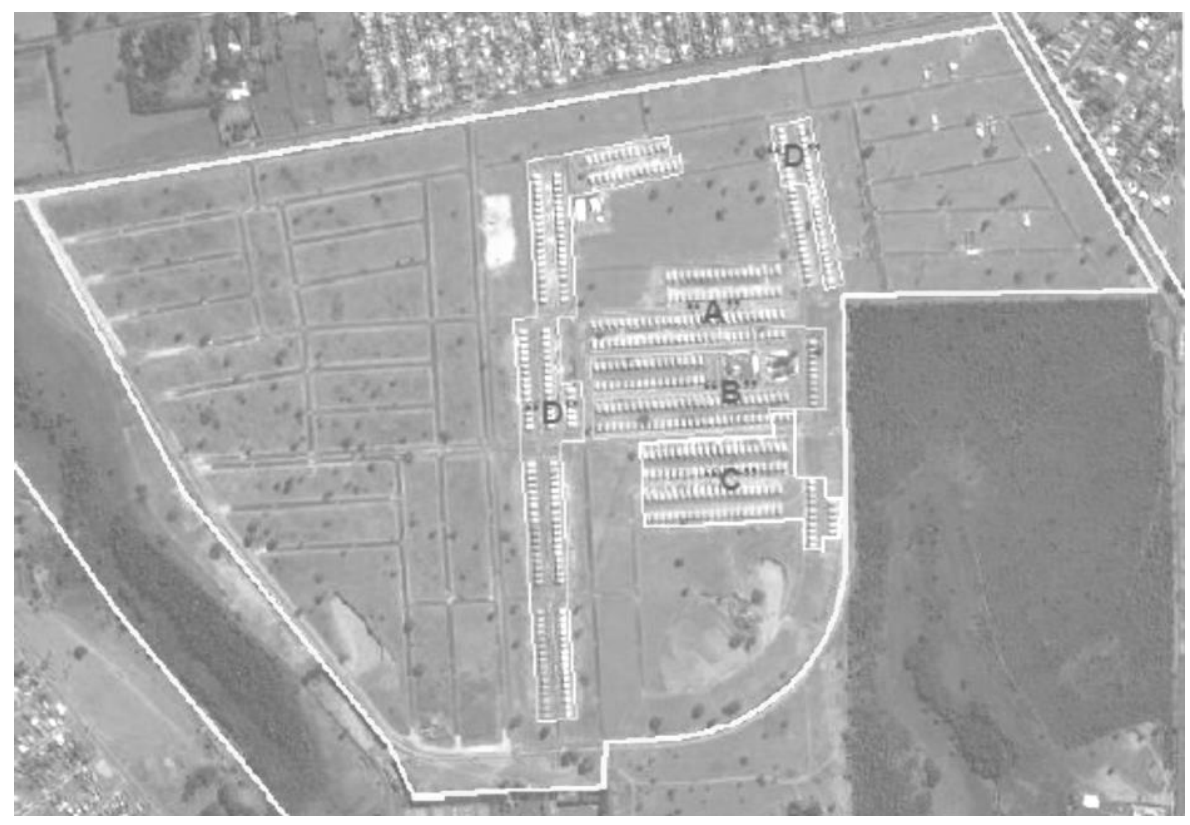

Figura 2 - Planilha de registro das manifestações patológicas

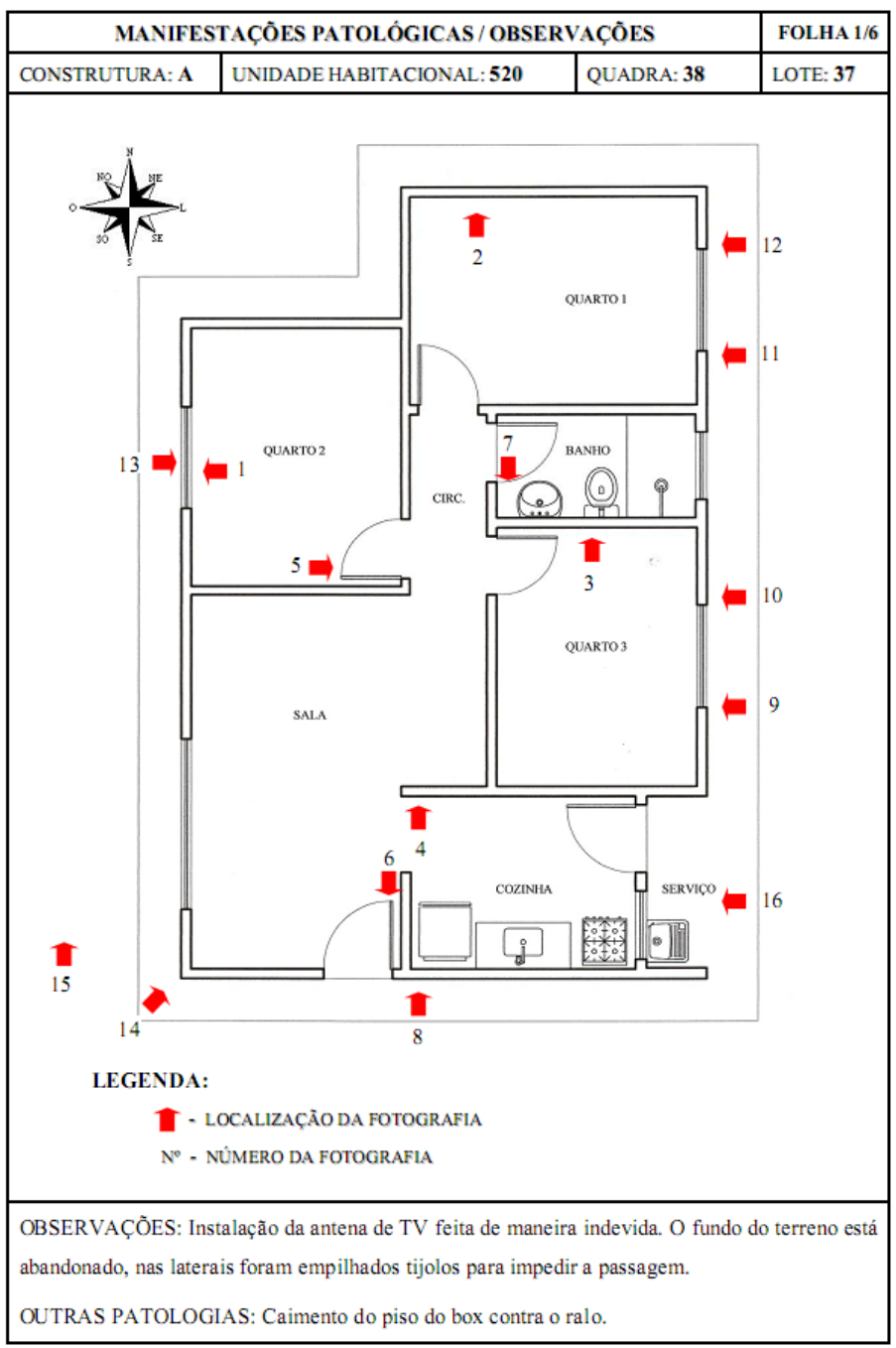


Figura 3 - Detalhe de manifestação patológica em parede

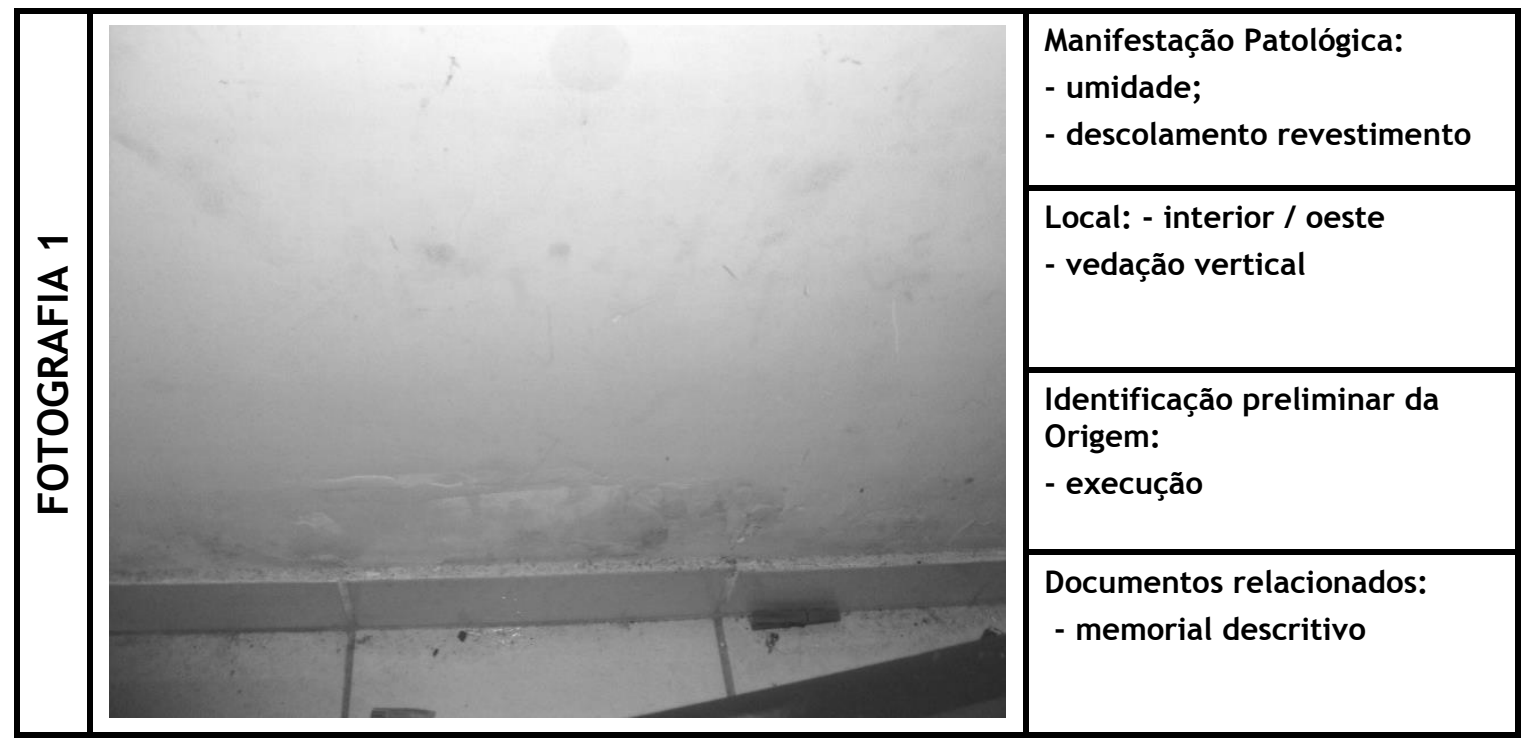

\section{Resultados da pesquisa}

\section{Sistemas construtivos}

Cada empresa construtora adotou um sistema construtivo de acordo com seu domínio tecnológico e com os requisitos especificados pelo cliente. A Tabela 1 elenca os sistemas construtivos adotados.

\section{Manifestações patológicas}

Com todos os dados recolhidos durante as visitas no conjunto habitacional, puderam-se analisar as manifestações patológicas levantadas.

Conforme citado anteriormente, as manifestações patológicas foram classificadas em quatro tipos: umidade, descolamento de revestimento, fissuras e irregularidade do acabamento.

Já para a realização do levantamento preliminar das origens das manifestações patológicas, foram adotadas as fases de produção e utilização pelas quais passam as edificações: projeto, execução, materiais e uso (manutenção e operação).
Identificaram-se o local de ocorrência das manifestações e os documentos que podem estar relacionados com elas.

De maneira geral, conforme Figura 4, observou-se que as principais manifestações patológicas identificadas foram fissuras $(43 \%)$; em seguida, com $22 \%$ de ocorrência, o descolamento de revestimento; depois, com percentual bem próximo (20\%), estão as irregularidades do acabamento; e, por último, porém preocupante, visto o grande número de fissuras, está a umidade, com 15\%. A preocupação vem do fato de que as fissuras fazem com que o desempenho das alvenarias de vedação quanto à estanqueidade seja baixo.

O levantamento preliminar das origens das manifestações patológicas apontou as anomalias originadas na execução como as mais frequentes (Figura 5), mostrando que a etapa de produção merece maior atenção nesse padrão de empreendimento.

Essa constatação é importante porque identifica a etapa da obra na qual devem ser tomadas medidas preventivas para evitar a reincidência dos problemas. 
Tabela 1 - Características do sistema construtivo empregado

\begin{tabular}{|c|c|c|c|c|c|c|c|c|c|}
\hline \multirow{3}{*}{ 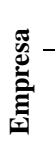 } & \multicolumn{9}{|c|}{ Sistema Construtivo } \\
\hline & \multirow{2}{*}{ Fundação } & \multirow{2}{*}{ Alvenaria } & \multirow{2}{*}{ Laje } & \multirow{2}{*}{ Cobertura } & \multicolumn{2}{|c|}{ Revestimento } & \multicolumn{2}{|c|}{ Esquadria } & \multirow{2}{*}{ Piso } \\
\hline & & & & & Interno & Externo & Interna & Externa & \\
\hline $\mathbf{A}$ & Radier & $\begin{array}{l}\text { Bloco de } \\
\text { Concreto }\end{array}$ & Maciça & $\begin{array}{c}\text { Estrutura } \\
\text { Madeira de } \\
\text { telha cerâmica }\end{array}$ & Gesso & $\begin{array}{l}\text { Reboco } \\
\text { Paulista }\end{array}$ & Madeira & Metálica & Cerâmica \\
\hline B & $\begin{array}{c}\text { Sapata } \\
\text { Corrida }\end{array}$ & $\begin{array}{l}\text { Bloco de } \\
\text { Concreto }\end{array}$ & Maciça & $\begin{array}{c}\text { Estrutura } \\
\text { Madeira de } \\
\text { telha cerâmica }\end{array}$ & Gesso & $\begin{array}{l}\text { Reboco } \\
\text { Paulista }\end{array}$ & Madeira & Metálica & Cerâmica \\
\hline $\mathbf{C}$ & Radier & $\begin{array}{l}\text { Bloco de } \\
\text { Concreto }\end{array}$ & Maciça & $\begin{array}{c}\text { Estrutura } \\
\text { Madeira de } \\
\text { telha cerâmica }\end{array}$ & Gesso & $\begin{array}{l}\text { Reboco } \\
\text { Paulista }\end{array}$ & Madeira & Metálica & Cerâmica \\
\hline D & Radier & $\begin{array}{l}\text { Bloco } \\
\text { Cerâmico } \\
\text { Furado }\end{array}$ & $\begin{array}{l}\text { Pré- } \\
\text { moldada }\end{array}$ & $\begin{array}{c}\text { Estrutura } \\
\text { Madeira de } \\
\text { telha cerâmica }\end{array}$ & Gesso & $\begin{array}{l}\text { Chapisco } \\
\text { e Reboco } \\
\text { Paulista }\end{array}$ & Madeira & Metálica & Cerâmica \\
\hline
\end{tabular}

Figura 4 - Tipos de manifestações patológicas ocorridas nas unidades habitacionais do conjunto construídas pela empresa $\mathrm{A}$

\section{Incidência das Manifestações Patológicas}

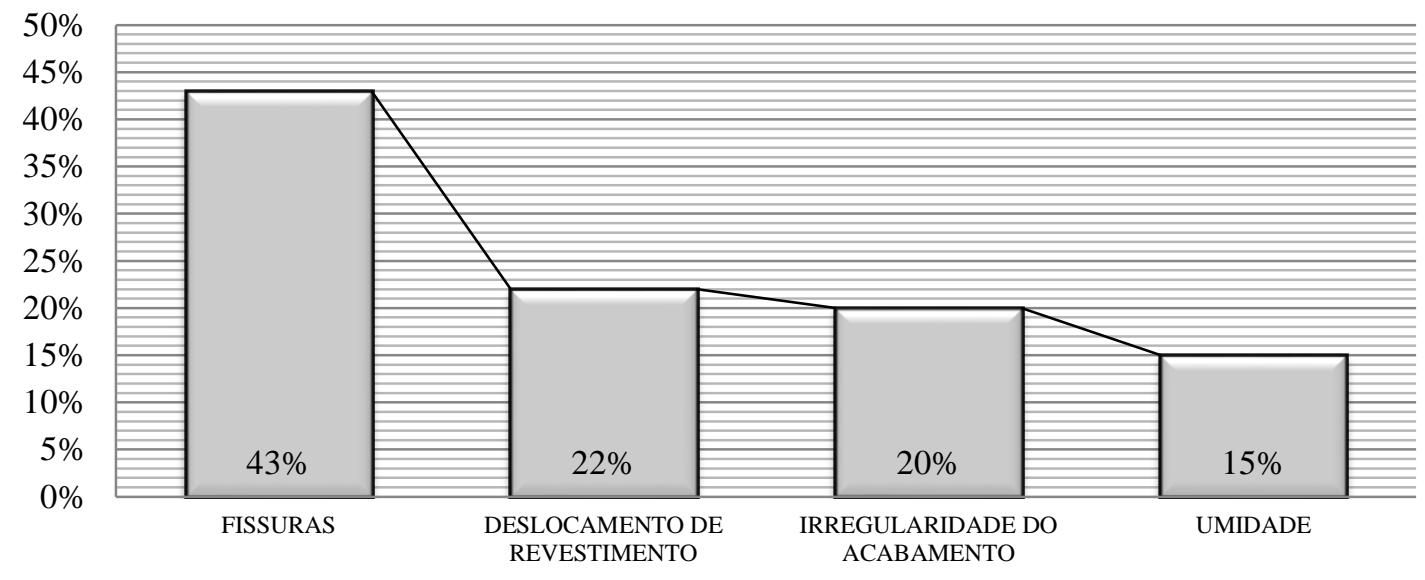

Figura 5 - Origem das manifestações patológicas ocorridas nas unidades habitacionais do conjunto construídas pela empresa $\mathrm{A}$

Levantamento Preliminar das Origens das Manifestações Patológicas

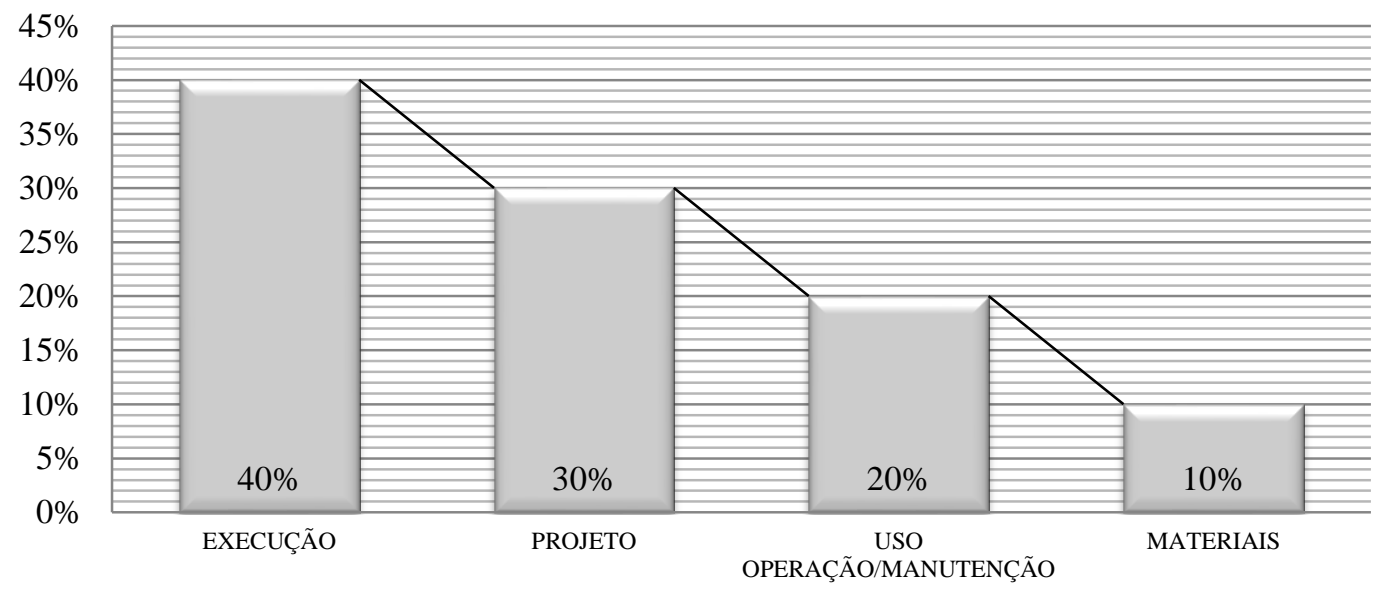


Na Figura 6 mostra-se que a maior incidência das manifestações patológicas localiza-se nos elementos construtivos da envoltória das edificações.

Como já citado anteriormente, é de grande importância a orientação solar da unidade habitacional. Confirmando essa afirmação, observa-se na Figura 7 o percentual de localização das manifestações patológicas existentes. A fachada oeste, a qual sofre a maior incidência do sol da tarde, é a que apresenta o maior número de manifestações.

Relacionando as manifestações patológicas com o levantamento preliminar das origens, seu local de ocorrência e os documentos influenciadores, temse o seguinte:

(a) as fissuras ocorreram, principalmente:

- no entorno das aberturas nas alvenarias, o que está relacionado diretamente com a falta de detalhamento em projeto; falta de informação no memorial descritivo quanto ao tamanho das vergas e contravergas, e falta do projeto executivo;

- no encontro entre laje e parede, sobre as portas de entrada principal, relacionado também, neste caso, à falta de detalhamento em projeto e de descrição no memorial descritivo quanto ao sistema de amarração entre paredes e lajes; e

- nas paredes sem aberturas do fundo da unidade, que podem estar relacionadas tanto ao projeto, que não previu uma proteção às paredes, de acordo com suas orientações solares, quanto ao memorial descritivo, que não determina a espessura do revestimento externo ou não descreve a maneira como deve ser feita a execução. (b) os descolamentos de revestimento ocorreram principalmente nas quinas das paredes externas e em locais úmidos, podendo, assim, estar relacionados: ao projeto, que não previu uma proteção às quinas das paredes; ao manual de uso e operação ou falta dele, que não orientou devidamente o uso; e, no caso dos locais úmidos, àquilo que gerou a umidade;

(c) as irregularidades do acabamento, como as manchas na pintura e reparos mal executados, estão relacionadas principalmente com a qualidade dos materiais ou com a execução, o que demonstra deficiência do memorial descritivo; e

(d) os pontos de umidade encontrados ocorreram geralmente em torno das esquadrias e próximo às fissuras encontradas nas paredes. Sendo assim, são consequências, no primeiro caso, da execução ou da qualidade do material, que, por sua vez, estão relacionados com a qualidade do memorial descritivo ou da obra; e, no segundo caso, são consequências de uma manifestação patológica apresentada anteriormente.

\section{Diretrizes para novos empreendimentos}

Diante dos dados analisados são apresentadas as diretrizes para as etapas de projeto, execução, uso e ocupação, relativas às edificações. Essas diretrizes são traçadas levando-se em consideração a documentação relacionada a cada uma das etapas. Elas buscam contribuir com a prevenção das manifestações patológicas em novos empreendimentos.

Figura 6 - Elementos construtivos atingidos pelas manifestações patológicas ocorridas nas unidades habitacionais do conjunto construídas pela empresa $\mathrm{A}$

Elementos Construtivos Atingidos

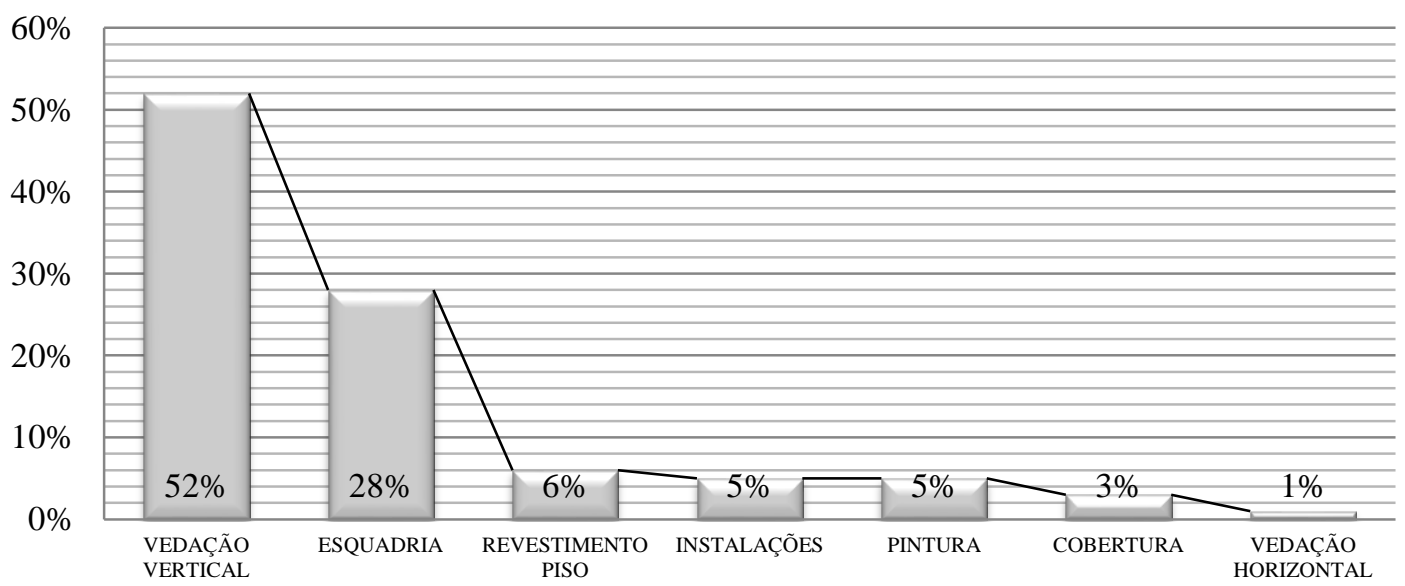


Figura 7 - Localização das manifestações patológicas ocorridas nas unidades habitacionais do conjunto construídas pela empresa $\mathrm{A}$

\section{Localização das Manifestações Patológicas}

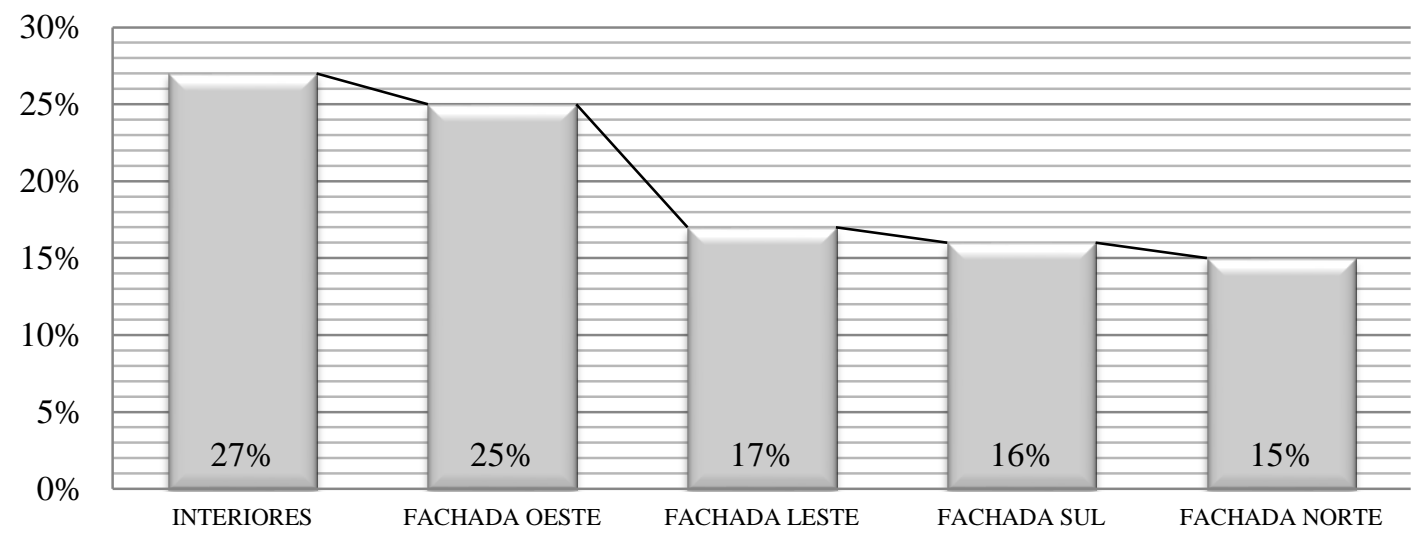

\section{Projeto}

A concepção do projeto deve levar em consideração, primeiramente, os requisitos do cliente. Observaram-se no estudo de caso realizado insatisfações dos usuários quanto à distribuição e dimensionamento dos ambientes, como, por exemplo, a cozinha. A cultura popular da região tem esse espaço da residência como ponto de encontro. Porém, neste projeto a cozinha não tem nenhum elemento que estimule a convivência; é praticamente um corredor.

Pela quantidade de intervenções realizadas nas construções, mesmo não sendo permitidas pelo Programa, fica claro o não atendimento às necessidades dos usuários, que vão desde o fator de identidade até aquelas mais básicas, funcionais. Como exemplo, tem-se:

(a) o fechamento do terreno nas mais diversas configurações de formas e cores;

(b) a cobertura da garagem;

(c) local para instalação de varal; e

(d) local para instalação de antena.

Sendo assim, propõe-se uma pesquisa de mercado bem detalhada sobre as necessidades dos futuros habitantes do conjunto habitacional programado.

Entende-se que, para esse nicho de mercado, por questões econômicas, não se oferece a personalização do projeto. Porém, algumas possibilidades de ampliação da unidade habitacional poderiam ser oferecidas. Evitar-se-ia o surgimento de várias manifestações patológicas originadas a partir dessas intervenções feitas de maneira improvisada.

A implantação da unidade no terreno é outro fator que deve ser bem estudado. Conforme a análise realizada, os aspectos topográficos e também os climáticos influenciam no surgimento de manifestações patológicas. Poder-se-ia propor soluções de proteção às áreas mais vulneráveis da unidade habitacional, como o prolongamento do beiral ou alguma barreira feita com vegetação.

Outra questão elementar, que merece ser destacada, é a falta de informações e mesmo erros apresentados em um projeto tão simples. $\mathrm{O}$ projeto deve ser bem detalhado, para que não ocorram problemas durante a execução. Todos os projetos complementares devem partir do arquitetônico; devem ser compatíveis.

Resumindo as questões levantadas sobre o projeto, são apresentadas as diretrizes para esta etapa:

(a) rever no $\mathrm{COE}$ as recomendações sobre a concepção de projeto. Devem ser mais objetivas, de maneira que não sejam apenas recomendações, mas que se tornem requisitos para a aprovação na fase de análise técnica;

(b) criar um requisito sobre a qualidade do projeto, avaliado a partir de concurso público (para nivelar o padrão exigido), o qual será delimitador para a contratação ou não da construtora;

(c) antes de se iniciar o projeto, fazer uma pesquisa de mercado bem detalhada sobre as necessidades dos futuros habitantes do conjunto habitacional programado;

(d) atender a todos os requisitos pertinentes à tipologia construtiva, dentre os tratados na norma de desempenho - NBR 15575 - Partes 1 a 6 (ABNT, 2013);

(e) entregar ao usuário, além do projeto arquitetônico básico, ou seja, aquele construído dentro do programa proposto, o projeto para futuras ampliações; 
(f) analisar e apresentar soluções para adequação da implantação à topografia de cada lote;

(g) analisar e apresentar soluções para a orientação solar da unidade habitacional de acordo com o lote;

(h) desenvolver o projeto executivo (projeto de produção para a obra); e

(i) compatibilizar os projetos complementares com o projeto arquitetônico.

\section{Execução}

De acordo com a proposta do trabalho, sobre a relação entre as manifestações patológicas e a documentação pertinente a cada etapa de desenvolvimento do empreendimento, na etapa de execução da obra, uma revisão do memorial descritivo, assim como dos projetos, apresenta-se como ponto de partida.

No processo da CAIXA, relativo ao conjunto habitacional objeto da pesquisa-base da dissertação de mestrado citada anteriormente, além do memorial descritivo e dos RAEs, não existem outros documentos ligados à execução da obra. Porém, outras informações podem ser obtidas a partir da pesquisa de Pereira (2008).

Sendo assim, apresentam-se a seguir as diretrizes traçadas a partir da análise dos documentos citados:

(a) adequação do memorial descritivo e projetos de acordo com os requisitos do gestor do empreendimento;

(b) construção de um protótipo para auxiliar no detalhamento do projeto executivo; no levantamento das necessidades de recursos de produção - material, mão de obra e custos; na atualização do orçamento e cronograma; na definição da sequência e fluxos de trabalho mais adequados; no treinamento da mão de obra;

(c) elaboração de um projeto de produção;

(d) exigência de um nível de qualificação da mão de obra; $\mathrm{e}$

(e) exigência de entrega de toda a documentação antes do início da obra, por meio de multas.

\section{Uso e ocupação}

Conforme citado anteriormente, o COE da CAIXA contém um Manual Técnico de Trabalho Social (MTTS), o qual dá orientações e disponibiliza diretrizes e informações para o técnico social responsável pela elaboração, implantação, registro, monitoramento e avaliação do Projeto de Trabalho Técnico Social (PTTS), bem como serve de apoio na implementação das ações técnicas sociais, desde a concepção do projeto até a etapa posterior à conclusão das obras e serviços (CAIXA, 2004).

O desenvolvimento desse trabalho favorece a compreensão dos usuários sobre o sistema de financiamento de seu imóvel e incentiva seu comprometimento com a conservação das unidades e com a preservação do espaço comunitário. Visa, ainda, dar legitimidade aos instrumentos que regulam as relações de vizinhança, constituindo-se em fator determinante sua satisfação (CAIXA, 2004).

O TTS deveria ser iniciado no momento da mudança dos arrendatários e ter duração máxima de seis meses. O grande problema é que ele, apesar de ser tão bem elaborado e, no caso do PAR, dispor de uma verba previamente reservada, nem sempre é implantado.

Foi o que ocorreu no conjunto habitacional analisado na pesquisa-base da dissertação de mestrado.

O pior é que a não efetivação do TTS já foi detectada em outros casos. Costa (2009) relata que em cinco empreendimentos analisados em sua pesquisa, apenas dois tiveram o TTS obrigatório realizado pela CAIXA.

Outros documentos que poderiam influenciar no uso e ocupação do empreendimento exigidos pela CAIXA no final da obra não foram encontrados no processo do empreendimento. Sendo assim, não puderam ser analisados.

Como diretrizes da etapa de uso e ocupação do empreendimento, destacam-se:

(a) implantação do TTS seguindo as orientações da CAIXA; e

(b) entrega dos seguintes documentos aos usuários de cada unidade habitacional:

- manual do proprietário com as devidas informações;

- projeto arquitetônico e complementares conforme construídos;

- projeto estrutural completo; e

- planta atualizada das redes da infraestrutura interna.

\section{Conclusão}

O trabalho realizado permitiu detectar um número considerável de manifestações patológicas nas unidades habitacionais.

Todas as unidades estudadas apresentavam manifestações patológicas. Entre as manifestações 
identificadas, $43 \%$ estão representadas por fissuras; $22 \%$ por descolamento de revestimento; $20 \%$ por irregularidades do acabamento; e $15 \%$ por presença de umidade.

As unidades foram erguidas por sistema construtivo convencional e integram um empreendimento operacionalizado pela Caixa Econômica Federal, a qual se embasa em diversos documentos, diretrizes e exigências quanto à qualidade da obra.

O objetivo do trabalho foi contribuir com o processo de projeto, gestão da construção e utilização das habitações de interesse social, ao chamar a atenção para os problemas recorrentes e oferecer diretrizes para a prevenção das manifestações patológicas em novos empreendimentos, possivelmente relacionadas aos documentos que regem o sistema.

Sendo assim, foram identificadas e descritas as manifestações patológicas encontradas nas unidades do conjunto habitacional e, a partir do exame documental, relacionadas com as possíveis origens de sua ocorrência. Nesse processo detectou-se deficiência ou ausência dos documentos envolvidos na implantação do empreendimento, como projetos com falhas e falta de detalhamento, memoriais incompletos $\mathrm{e}$ ausência de assistência aos moradores.

Finalmente, propuseram-se as diretrizes a partir da relação entre as manifestações patológicas e a documentação pertinente a cada etapa do empreendimento: projeto, execução, uso e ocupação, visando à prevenção das manifestações em novos empreendimentos.

A pesquisa de campo caracterizou a principal fonte de informação utilizada para a compreensão dos documentos envolvidos no programa habitacional, contribuindo significativamente para a proposição das diretrizes.

O conjunto de diretrizes proposto pelos autores do artigo não tem o formato de um modelo. É essencial que se analisem todos os itens apresentados e que se verifique a possibilidade de adequá-los à realidade do empreendimento.

Conclui-se, portanto, que não basta existir um elenco de documentos a serem apresentados; eles são imprescindíveis, mas devem ser utilizados de fato, e não somente para atender a uma formalidade. Eles devem servir de parâmetro para o alcance do desempenho da edificação residencial.

As constatações da pesquisa corroboram a proposta de Cleto et al. (2011) a respeito da necessidade de criação do Códigos de Práticas no
Brasil, formalizando boas práticas, para tornar-se referência e contribuir para a melhoria da qualidade de atividades e seus resultados, podendo ser incorporado a uma estrutura de regulamentação e tornar-se não somente orientativo, mas também um instrumento regulatório e/ou contratual de empresas, instituições ou de um setor.

Devido às dificuldades encontradas na realização desta pesquisa, sugere-se que pesquisas similares levem em consideração a metodologia proposta por Berr e Formoso (2012) para avaliação da qualidade de processos construtivos em empreendimentos habitacionais de interesse social.

Espera-se que este trabalho possa trazer contribuição a este nicho da construção civil, que ainda deverá ser muito explorado, principalmente em países em desenvolvimento como o Brasil.

\section{Referências}

ASSOCIAÇÃO BRASILEIRA DE NORMAS TÉCNICAS. NBR 15575-1: edificações habitacionais: desempenho: parte 1: requisitos gerais. Rio de Janeiro, 2013.

\section{ASSOCIAÇÃO BRASILEIRA DE NORMAS} TÉCNICAS. NBR 15575-2: edificações habitacionais: desempenho: parte 2: requisitos para os sistemas estruturais. Rio de Janeiro, 2013.

\section{ASSOCIAÇÃO BRASILEIRA DE NORMAS TÉCNICAS. NBR 15575-3: edificações} habitacionais: desempenho: parte 3: requisitos para os sistemas de pisos. Rio de Janeiro, 2013.

\section{ASSOCIAÇÃO BRASILEIRA DE NORMAS} TÉCNICAS. NBR 15575-4: edificações habitacionais: desempenho: parte 4: requisitos para os sistemas de vedações verticais internas e externas: SVVIE. Rio de Janeiro, 2013.

\section{ASSOCIAÇÃO BRASILEIRA DE NORMAS TÉCNICAS. NBR 15575-6: edificações} habitacionais: desempenho: parte 6: requisitos para os sistemas hidrossanitários. Rio de Janeiro, 2013.

AZEVEDO, S. L. et al. Levantamento e Análise das Manifestações Patológicas no PAR Regente (Pelotas/RS) e Possíveis Medidas Profiláticas. In: ENCONTRO NACIONAL DE TECNOLOGIA DO AMBIENTE CONSTRUÍDO, 12., Fortaleza, 2008. Anais..., Fortaleza, 2008.

BERR, L. R.; FORMOSO, C. T. Método Para Avaliação da Qualidade de Processos Construtivos em Empreendimentos Habitacionais de Interesse Social. Ambiente Construído, Porto Alegre, v. 12, n. 2, p. 77-96, abr./jun. 2012. 
BLANCO, M. Política Habitacional: o novo desenho do setor. Revista Construção Mercado, São Paulo, v. 94, n. 62, p. 30-37, maio 2009.

BRASIL. Lei Federal $n^{\circ} 11.474$, de 15 de maio de 2007, que altera a Lei $\mathrm{n}^{\circ} 10.188$, de 12 de fevereiro de 2001, que cria o Programa de Arrendamento Residencial, institui o arrendamento residencial com opção de compra, e Lei n. 11.265

[...]. Diário Oficial da União, Brasília, 15 de maio de 2007.

BRASIL. Lei Federal n ${ }^{\circ} 11.888$, de 24 de dezembro de 2008, que assegura às famílias de baixa renda assistência técnica pública e gratuita para o projeto e a construção de habitação de interesse social e altera a Lei $\mathrm{n}^{\circ} 11.124$, de 16 de junho de 2005. Diário Oficial da União, Brasília, 24 de dezembro de 2008.

BRITO, J. N. S. Retroalimentação do Processo de Desenvolvimento de Empreendimentos de Habitação de Interesse Social a Partir de Reclamações de Usuários: estudo no Programa de Arrendamento Residencial. Porto Alegre, 2009. Dissertação (Mestrado em Engenharia Civil) Engenharia Civil, Universidade Federal do Rio Grande do Sul, Porto Alegre, 2009.

CAIXA ECONÔMICA FEDERAL. Caderno de Orientações de Empreendimentos - COE. Belo Horizonte: CAIXA, 2004.

CAIXA ECONÔMICA FEDERAL. Cartilha do PAR, 2008. 2008. Disponível em:

<http://www.caixa.gov.br>. Acesso em: 23 abr. 2009.

CAIXA ECONÔMICA FEDERAL. Programas de Habitação - PAR. Disponível em: <http://www.caixa.gov.br/pj/pj_social/mg/habitaca o_social/par/saiba_mais.asp> Acesso em: 20 jan. 2010.

CARMONA FILHO, A. Panorama da Edificação Sob a Ótica da Patologia. Conexão AEC, 2009. Disponível em:

<http://www.aecweb.com.br/artigo/comunidade/12 76/antonio-carmona-filho/panorama-da-edificacaosob-a-otica-da-patologia.html>. Acesso em: 5 mar. 2010.

CLETO, F. da R. et al. Códigos de Práticas: uma proposta de documentos técnicos de referência de boas práticas para a construção de edifícios no Brasil. Ambiente Construído, Porto Alegre, v. 11, n. 2, p. 7-19, abr./jun. 2011.
COSTA, D. C. B. Gestão Pós-Ocupação em Edifícios Reabilitados Para Habitação de Interesse Social no Centro de São Paulo. São Paulo, 2009. 164 f. Dissertação (Mestrado em Engenharia Civil) - Escola Politécnica, Universidade de São Paulo, São Paulo, 2009.

FIESS, J. R. F. et al. Causas da Ocorrência de Manifestações Patológicas em Conjuntos Habitacionais do Estado de São Paulo. In: CONFERÊNCIA LATINO-AMERICANA DE CONSTRUÇÃO SUSTENTÁVEL, ENCONTRO NACIONAL DE TECNOLOGIA DO AMBIENTE CONSTRUÍDO, 10., São Paulo, 2004. Anais..., São Paulo, 2004.

HELENE, P. R. L. Manual Para Reparo, Reforço e Proteção de Estruturas de Concreto. 2. ed. São Paulo: Pini, 1992.

MÁXIMO, W. Investimento em Habitação e Saneamento Soma R\$ 146,3 Bilhões Até 2010. Agência Brasil, 2007. Disponível em: $<$ http://agenciabrasil.ebc.com.br/noticia/2007-0122/investimento-em-habitacao-e-saneamentosoma-r-1463-bilhoes-ate-2010>. Acesso em: 3 mar. 2008.

MINISTÉRIO DAS CIDADES. Secretaria Nacional de Habitação. Déficit Habitacional no Brasil 2007. Brasília, DF, 2009.

ORNSTEIN, S. W.; ROMÉRO, M. A. (Cols.). Avaliação Pós-Ocupação (APO) do Ambiente Construído. São Paulo: Studio Nobel; Edusp, 1992.

PAN, W.; GIBB, A. G. F.; DAINTY, A. R. J. Perspectives of UK Housebuilders on the Use of Offsite Modern Methods of Construction.

Construction Management and Economics, v. 25, n. 2, p. 183-194, 2007.

PEREIRA, E. A. Diretrizes de Gestão Para Obras Habitacionais de Interesse Social. Uberlândia, 2008. 174 f. Dissertação (Mestrado em Engenharia Civil) - Engenharia Civil, Universidade Federal de Uberlândia, Uberlândia, 2008.

PROGRAMA BRASILEIRO DA QUALIDADE E PRODUTIVIDADE DO HABITAT. [Programa]. Disponível em: <http://cidades.gov.br/pbqph/index.php>. Acesso em: 24 set. 2008.

REIS, A. Estudo Alerta Para Desafios do Novo Perfil do Programa de Arrendamento Familiar. Revista Eletrônica Habitare, v. 8, dez. 2008. Disponível em:

<http://www.habitare.org.br/ConteudoGet.aspx?C D_CONTEUDO=510>. Acesso em: $11 \mathrm{dez} .2008$. 
RIBEIRO, J. L. D.; ECHEVESTE, M. E. Dimensionamento da Amostra em Pesquisa de Satisfação de Clientes. In: ENCONTRO NACIONAL DE ENGENHARIA DE PRODUÇÃO, 18., Niterói, 1998. Anais... Niterói, 1998.

ROMÉRO, M. A.; ORNSTEIN, S. W. Avaliação Pós-Ocupação: métodos e técnicas aplicados à habitação social. Porto Alegre: Antac, 2003. (Coleção Habitare).

ROMÉRO, M. A.; VIANNA, N. S. Procedimentos Metodológicos Para Aplicação de Avaliação PósOcupação em Conjuntos Habitacionais Para a População de Baixa Renda: do desenho urbano à unidade habitacional. In: ABIKO, A. K.; ORNSTEIN, S. W. (Ed.). Inserção Urbana e Avaliação Pós-Ocupação (APO) da Habitação de Interesse Social. São Paulo: Fauusp, 2002. (Coletânea Habitare, v. 1, cap. 8).
ROY, R.; LOW, M.; WALLER, J. Documentation, Standardization and Improvement of the Construction Process in House Building. Construction Management and Economics, London, v. 23, n. 1, p. 57-67, jan. 2005.

SILVA, F. B.; BARROS, M. M. S. B.

Planejamento de Processos de Construção Para a Produção Industrializada de Edifícios

Habitacionais: apresentação de um plano de ação. São Paulo: EPUSP, 2013. 21 p. (Boletim Técnico da Escola Politécnica da USP, Departamento de Engenharia de Construção Civil, BT/PCC/580).

SOUZA, V. C. M.; RIPPER, T. Patologia, Recuperação e Reforço de Estruturas de Concreto. São Paulo: Pini, 1998.

THOMAZ, E. Tecnologia, Gerenciamento e Qualidade na Construção. São Paulo: Pini, 2001. 